\title{
NATURAL CONVECTION HEAT TRANSFER ANALYSIS OF ATR FUEL ELEMENTS
}

\author{
Michael. A. Langerman \\ Published May 1992 \\ Idaho National Euginetring Laboratory \\ EG\&G Idaho, Inc. \\ Idaho Falls, Idaho 83415 \\ Prepared for the \\ U.S. Department of Energy \\ Orfice of Nuclear Energy \\ Under DOE Idaho Field Orfice \\ Contract DF-AC07-761001570
}

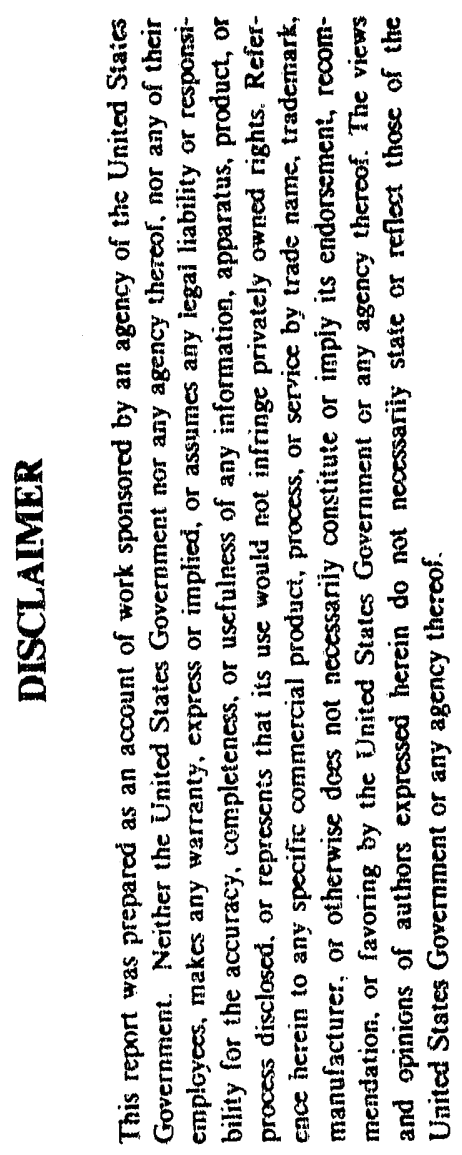




\begin{abstract}
AHSTRACT
Natural convection air cooling of the Advanced Test Reactor (ATR) fuel assemblies is analyzed to determine the level of decay heat that can be removed without exceeding the melting ternperature of the fuel. The study was conducted to assist in the level 2 PRA analysis of a hypothetical ATR water canal draining accident. The heat transfer process is characterized by a very low Rayleigh number $\left(\mathrm{Ra} \approx 10^{-5}\right)$ and a high temperature ratio. Since neither data nor analytical models were available for $\mathrm{Ra}<0.1$, an analytical approach is presented based upon the integral boundary layer equations. All assumptions and simplifications are presented and assessed and two models are developed from similar foundations. In one model, the well-known Boussinesq approximations are employed, the results from which are used to assess the modeling philosophy through comparison to existing data and published analytical results. In the other model, the Boussinesq approximations are not used, thus making the model more general and applicable to the ATR analysis.
\end{abstract}




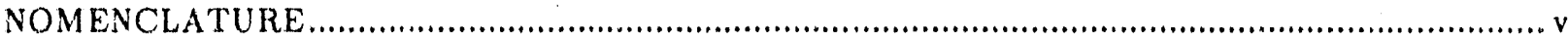

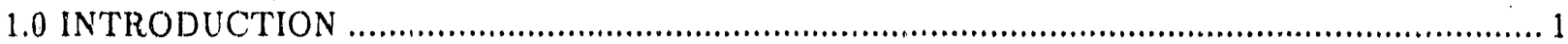

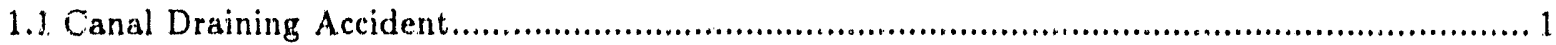

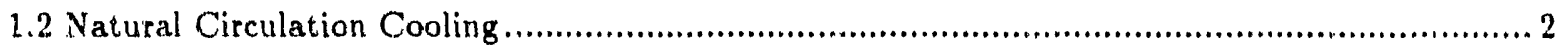

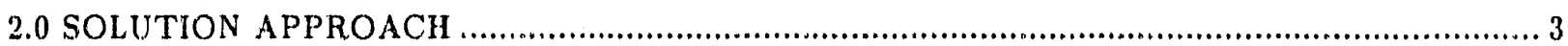

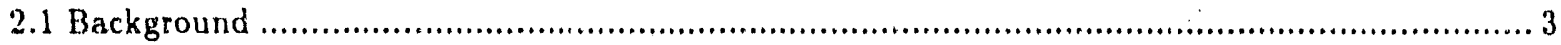

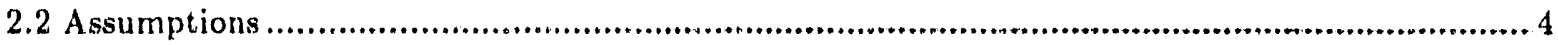

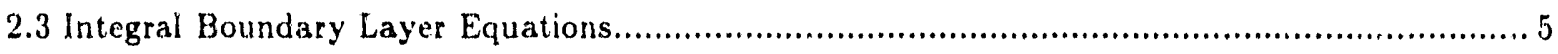

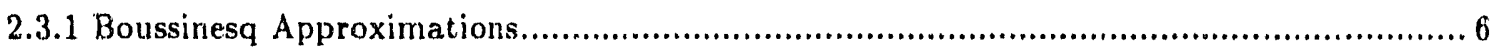

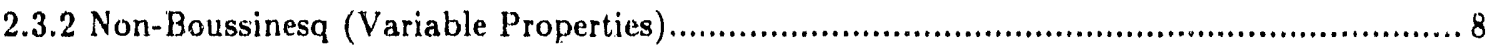

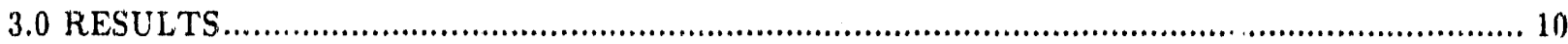

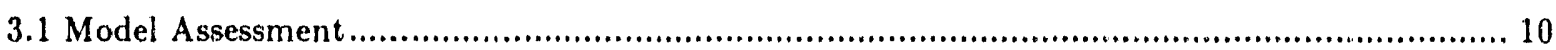

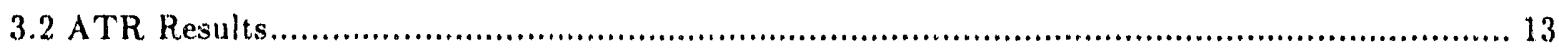

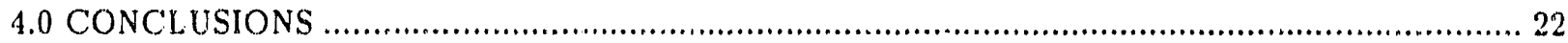

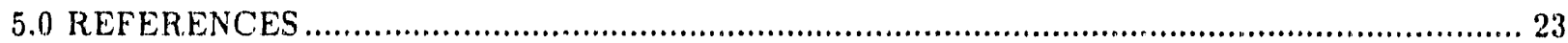




\section{FIGURES}

1. Cross-sectional view of an ATR fuel element (measurements in inches) ...................................... 1

2. Average channel Nusselt number, Boussinesq model ................................................................ 11

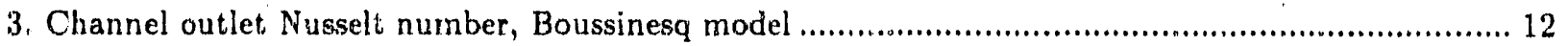

4. Dimensionless flow rate versus channel length, Boussinesq model .............................................. 12

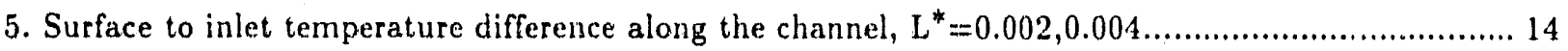

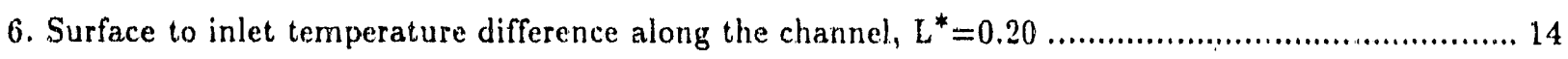

7. Maximum calculated temperaiture versus input heat flux......................................................... 15

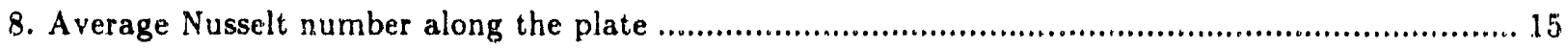

9. Channel mass flow rate versus input heat flux ................................................................ 17

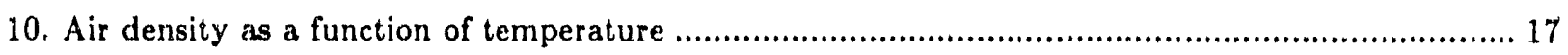

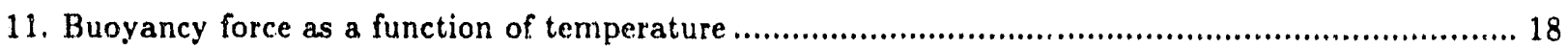

12. Air viscosity as a function of temperature ..................................................................... 18

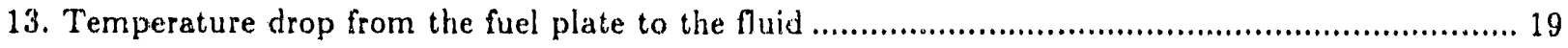

14. Ratio of local to average volumetric heat generation rate along fuel element ............................. 20

15. Dimensionless temperature calculated from constant and variable power profiles ......................... 20 


$\begin{array}{ll}\mathrm{a}_{0}, \mathrm{~b}_{0} & \text { profile coefficients } \\ \mathrm{b} & \text { width between fuel plates (gap) } \\ \mathrm{h} & \text { heat transfer coefficient } \\ \beta & \text { coefficient of thermal expansion } \\ \mathrm{V} & \text { mean fluid velocity } \\ \mathrm{u} & \text { x-direction velocity } \\ \ell & \text { gap half width, } \mathrm{b} / 2 \\ \mathrm{~L} & \text { length of fuel plate } \\ { }^{\tau_{0}} & \text { wall shear stress } \\ \rho & \text { fluid density } \\ \mathrm{g}_{i} & \text { gravitationai constant } \\ \mathrm{p} & \text { pressure } \\ \mathrm{k} & \text { fluid thermal conductivity } \\ \mathrm{T}^{*} & =\left(\mathrm{T}-\mathrm{T}_{\infty}\right) / \mathrm{q}^{\prime}(\mathrm{b} / \mathrm{k}) \\ y & \text { half the fuel plate thickness } \\ \hat{\mathrm{k}} & \text { fuel plate thermal conductivity } \\ \mathrm{c}_{\mathrm{p}} & \text { specific heat } \\ \mathrm{T} & \text { fluid temperature } \\ \mathrm{T}_{0} & \text { channel wall temperature } \\ \mathrm{T}_{\mathrm{m}} & \text { bulk fluid temperature } \\ \mathrm{T}_{\infty} & \text { channel inlet temperature } \\ g & \text { plate width }\end{array}$

$\begin{array}{ll}\mathrm{q}^{\prime \prime \prime} & \text { heat generation rate } \\ \mu & \text { fluid dynarnic viscosity } \\ \alpha & \text { fluid thermal diffusivity } \\ \nu & \text { fluid kineinatic viscusity } \\ \eta & =\mathrm{y} / \ell \\ \mathrm{q}^{\prime} & \text { heat flux per unit depth } \\ \dot{m} & \text { mass flow rate } \\ \mathrm{x}, \mathrm{y} & \text { Cartesian coordinates } \\ t & \text { fuel thickness } \\ \mathrm{x}^{*} & =\mathrm{x} / \mathrm{L} \\ \mathrm{M}^{*} & =\mathrm{Vb} / \nu \mathrm{Gr} \\ \mathrm{L}^{*} & =\mathrm{Pr} / \mathrm{Ra} \\ \mathrm{Q} & =\left.\rho c_{\mathrm{p}} \int \mathrm{u}\left(\mathrm{T}-\mathrm{T}_{\infty}\right) \mathrm{dy}\right|_{\mathrm{x}=\mathrm{L}}\end{array}$

nondirnensional groups

Nu Nusselt nurnber, hb/k

Gr Grashof number, $\mathrm{g} \beta \mathrm{q}^{\prime} \mathrm{b}^{4} / \nu^{2} \mathrm{k}$

$\mathrm{Gr}_{\mathrm{L}} \quad$ Grashof number, $\mathrm{g} \beta \mathrm{q}^{\prime} \mathrm{L}^{4} / \nu^{2} \mathrm{k}$

$\operatorname{Pr} \quad$ Prandtl number, $\nu / \alpha$

- Ra Rayleigh number, $\operatorname{PrGr}(b / L)$

Bi Biot number, $h 9 / \hat{k}$ 


\subsection{INTRODUCTION}

The Advanced Test Reactor (ATR) at the Idaho National Engineering Laboratory is a pressurized, forced-flow; light water reactor with a design power rating of 250 megawatts. The ATR core consists of 40 fuel elements arranged in an annular serpentine array. Each element consists of 19 parallel curved plates of different width, as shown in Figure 1. The plates are fabricated of fully enriched uranium aluminide dispersed in and clad with an aluminum alloy.

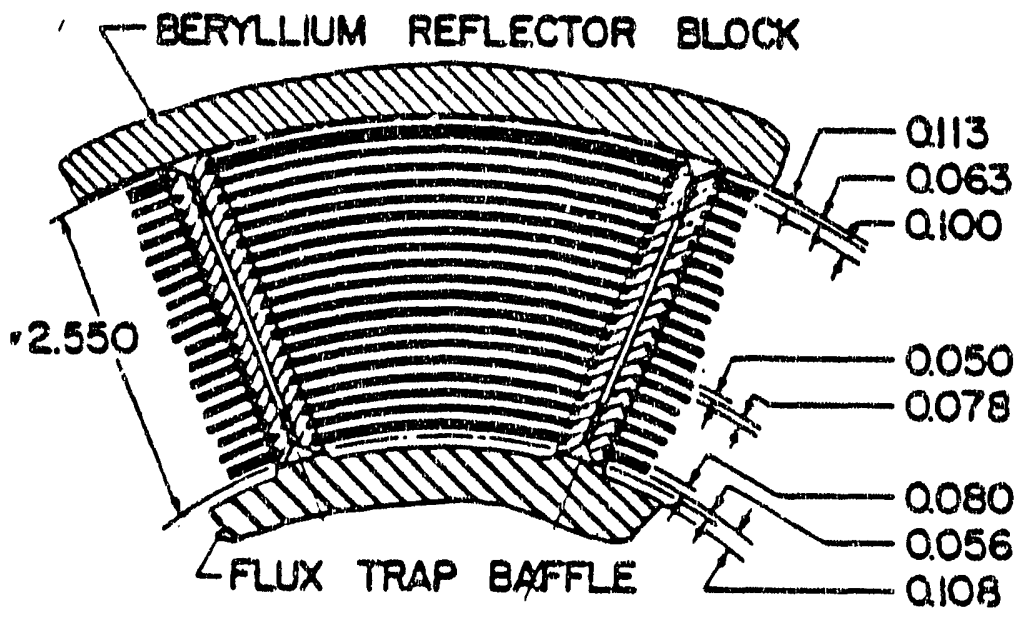

Figure 1. Crose-sectional view of an ATR fuel element (messurements in inches).

\subsection{Canal Draining Aecident}

The ATR is accessible by a system of interconnected water canals between the reactor room, the storage canal area, and the critical facility. These canals are designed to provide for safe handling of radioactive materials and for short term storage of fuel assemblies. While a canal draining accident is a very low prolability event, ${ }^{1}$ the potential risks are relatively high due to the large number of fuel elements involved (600) and because any fission product release would occur outside the gas-tight area 
of the ATR confinement. Consequently, the risks'from this accident scenario are presently being analyzed as part of the development of a level 2 probabilistic risk assessment (PRA). This report assists in the PRA analysis by addressing one aspect of the accident scenario, the heat transfer process along the fuel plates subsequent to water drainage. The objective of this study is to determine the level of decay heat that can be removed, via natural circulation of air through the fuel elements, without exceeding the melting temperature of the fuel $(\approx 900 \mathrm{~K})$. This information will then be used in the PRA analysis to calculate the amount of fuel, based upon the fuel life cycle, that is above this critical power level and thus may be assumed to melt. It is assumed, in the analysis herein, that there is sufficient room below the fuel storage racks for air to flow freely up through the individual fuel plate channels.

\subsection{Natural Circulation Cooling}

Natural circulation analyses are complicated by the fact that the flow field is coupled to the heat transfer process and the system geometry via buoyancy forces and viscous forces, respectively. Whereas efforts to model this type of problem have concentrated primarily on isoflux or isothermal surfaces, in the present analysis complications arise due to a varying heat fux along the surface of the fuel plate resulting from a nonuniform power generation rate. In addition, data available in the literature is restricted to system conigurations where the aspect ratio, $L / b$ (plate length to gap width ratio), is less than 100 and for Rayleigh numbers, Ra, greater than 0.1 . The ATR fuel assemblies are significantly outside these parametric limits with an $\mathrm{L} / \mathrm{b} \approx 600$ and an associated $\mathrm{Ra} \approx 10^{-5}$. Consequently, the applicability of existing data to the ATR system analysis is questionable. Although there exist multidimensional computer codes that have the potential capability to resolve this coupled fluid/solid heat transfer problem, the large aspect ratio that exists within the fuel assemblies would necessitate a very fine discretization, making the calculation costly with no assurance the complex natural convection portion of the computation would converge.

With these concerns in mind, the analysis approach decided upon, and discussed in detail in Section 2, was to solve the heat transfer problem using the parabolic integral boundary layer equations, and, if necessary (due to temperature gradients within the fuel element), couple the solution to a heat conduction calculation. This approach does not rely upon heat transfer correlations, since the boundary layer equations are used to solve directly for the surface temperature along the fuel plate. To assess the model, results from calculations are compared, in Section 3, to applicable data at Ra numbers and $L / b$ ratios where such data exist. Results from the ATR analysis are also presented in Section 3. Conclusions are presented in Section 4. 


\subsection{SOLUTION APPROACII}

The method used to solve the natural convection heat transfer problem is discussed in the following paragraphs. A brief background is given followed by a short discussion of assumptions employed. Next an account of the boundary layer equations is given including the finalized equations and simp! !fications used here.

\subsection{Background}

Natural convection flows occur in many areas of applied engineering in addition to nuclear reactor cooling systems, for example atmospheric and oceanic circulation and in electric machinery. The flow is a buoyancy-induced motion resulting from body forces acting on density gradients which, in turn, arise from mass concentration and/or temperature gradients in the fluid.

The problem of cooling heated, vertical, parallel plates by natural convection has drawn considerable attention due primarily to the interest generated within the electronics industry. The history of the modeling of such problems has been a sequence of refinements and successive approximations. Elenbass, ${ }^{3}$ in an early model, showed that the Nusselt number is proportional to the channel Ra. Later, Aung ${ }^{4}$ showed that, for symmetric and asymmetric heating of the plates, the temperature field is fully developed prior to or at the same time as the velocity field indicating that the thermal development length is independent of the $\mathrm{Pr}^{1}$. This result is different from that of forced convection where the ratio of the development length for velocity and temperature is a function of $\mathrm{Pr}$. Aung et al., 5 found that the channel outlet velocity and temperature profiles are still developing for $\mathrm{Ra} \geq 0.14$. The experiments of Wirtz and Stutzman ${ }^{6}$ agreed well with the analytical model of Aung (see Reference 5).

As mentioned, the ATR analysis is different from that of earlier investigations due to the extremely low $\mathrm{Ra}\left(\approx 10^{-5}\right.$ ) and the large aspect ratio $(\approx 600)$. In addition, the resultant fluid temperature rise along the fuel element renders the Boussinesq assumption made in the analyses of References 2-7 of questionable validity here. Therefore, it was decided to approach the problem from first principles and apply simplifying assumptions only as needed. The approach is discussed below following a brief discussion of the underlying assumptions employed.

\footnotetext{
${ }^{1}$ This independence upon $\operatorname{Pr}$ was later shown to be ralid only for $L / b \geq 15$.
} 


\subsection{Assumptions}

The analysis presented is constrained by simplifying assumptions. These assumptions, or simplifications, include treating the flow as laminar boundary layer flow and assuming the velocity and temperature fields are adequately represented as two-dimensional fully developed fields between vertical parallel plates. These constraints and the possible effects they have on the calculated results are addressed briefly below.

The actual geometry under consideration is annular but the ratio of the radius of curvature for a fuel plate to the distance between fuel plates (gap) ranges from approximately 40 to 80 , thus justifying the simplification of treating the geometry as parallel, vertical, flat plates. Similarly, the ratio of the fuel plate width to the gap between plates ranges from approximately 30 to 60 , thereby justifying the assumption of two-dimensional flow.

Over the range of heat fluxes relevant to this analysis, the $\operatorname{PrGr}_{\mathrm{L}}$ is on the order of $30^{10}$, where $\mathrm{Gr}_{\mathrm{L}}$ is calculated using the overall plate length. As mentioned, the flow is assumed laminar, which, based upon results from Miyamoto, et al., is a good assumption for a $\operatorname{PrGr}_{\mathrm{L}} \leq 10^{11-12}$.

Application of the boundary layer equations implies thermal diffusion in the flow direction may be neglected. At an $\mathrm{L} / \mathrm{b}$ of approximately 600 , this assumption is a good assumption based upon results from Reference 2 , that show the effects from vertical diffusion are insignificant for $L / b \geq 15$.

Assuming fully developed velocity and temperature profiles, and thereby neglecting the effect of the thermal entry length, is a nonconservative assurnption regarding critical power level estimates but probably of negligible consequence here due to the large aspect ratio, L/b. Ramanathan and Kumar (see Reference 2) show that for an aspect ratio of only 15 the flow is fully developed within $17 \%$ of the channel entrance. As implied in their results, this percentage will decrease with increasing aspect ratio.

It should be noted that all the heat generated within the fuel is assumed dissipated via natural convection. This assumption will likely lend to conservative estimates of the critical power level since some heat loss may be expected out the ends and sides of the fuel ilements due to radiation ${ }^{8} \ldots$ due to conduction in the fluid?

Finally, the validity of the Boussinesq approximation is addressed. This approximation includes the assumption of constant properties except for density in the momentum equation when it directly influences buoyancy forces. Also neglected are any frictional heating effects. The potential consequences of these approximations are discussed in the following section. 


\subsection{Integral Boundary Layer Equations}

The integral boundary layer equations 10 are written below in Cartesian coordinates where the $\mathrm{x}$ -direction is the direction of flow along the fuel plate and the $y$-direction is the outward direction normal to the fuel plate.

Mass: $\quad \frac{\mathrm{d}}{\mathrm{dx}} \int_{0}^{\ell} \rho \mathrm{udy}=0$

Momentum:

$$
-\frac{\mathrm{d}}{\mathrm{dx}} \int_{0}^{\ell} \rho \mathrm{u}^{2} \mathrm{dy}-r_{0}-\int_{0}^{\ell} \rho \mathrm{gdy}-\frac{\mathrm{dp}}{\mathrm{d} x} \ell=0
$$

and

Energy:

$$
\frac{d}{d x} \int_{0}^{\ell} \rho c_{p} u\left(T-T_{\infty}\right) d y-\frac{q^{\prime}}{g}=0
$$

where $g$ is the width of the plate. At this point, (2) is unconstrained except for the assumption of fully developed flow.

The facility in applying the integral boundary layer approach above lies in the ease of application and in the resulting solution of ordinary differential equations as opposed to partial differential equations. The accuracy obtained, however, is dependent upon how well the velocity and temperature distributions and the wall shear stress are represented.

The wall shear stress, under the assumption of laminar Newtonian flow, comes from Newton's law of viscosity, which states,

$$
\tau_{0}=\left.\mu \frac{\partial \mathrm{u}}{\partial \mathrm{y}}\right|_{\mathrm{y}=0}
$$

and requires information regarding the velocity profile. For this analysis, the velocity profile is assumed parabolic as,

$$
u=a_{0}+\left(a_{1}+a_{2} y\right) y
$$

where the coefficients $a_{0}, a_{1}$, and $a_{2}$ will be determined from boundary conditions. Simila.ly, the temperature profile is assumed parabolic as,

$$
\mathrm{T}=\mathrm{b}_{0}+\dot{*}^{\cdot}\left(\mathrm{b}_{1}+\mathrm{b}_{2} \mathrm{y}\right) \mathrm{y} \text {. }
$$


The validity of these assumptions lies in how accurately the results obtained reflect available data or represent known solutions (assessed in a later section). The boundary conditions are

$$
\begin{array}{ll}
\text { at } \quad \mathrm{y}=0, & \mathrm{u}=0 \text { and } \mathrm{T}=\mathrm{T}_{0} \\
\mathrm{y}=\ell, & \frac{\partial \mathrm{u}}{\partial \mathrm{y}}=\frac{\partial \mathrm{T}}{\partial \mathrm{y}}=0 .
\end{array}
$$

Substituting (7) into (5) and (6) results in

$$
u=\frac{3}{2} V \eta(2-\eta)
$$

and

$$
\mathrm{T}=\mathrm{T}_{0}+\frac{5}{4}\left(\mathrm{~T}_{0}-\mathrm{T}_{\mathrm{m}}\right)\left(\eta^{2}-2 \eta\right)
$$

where $\eta=\frac{y}{\ell}, V=\frac{1}{\ell} \int u d y$, and $T_{m}=\frac{1}{\ell V} \int u T d y$.

Here, as in most natural circulation analyses, the density is cast as a linear function of temperature. In doing so, compressibility effects are neglected, which is a good approximation for thermally induced natural convection problems. ${ }^{11}$ Expanding the density in a Taylor Series around some average value of $T$, say $\bar{T}$, results in

$$
\rho=\bar{\rho}[1-\bar{\beta}(\mathrm{T}-\overline{\mathrm{T}})],
$$

where $\bar{\beta}$ is the coefficient of therrual expansion defined as

$$
\beta=-\frac{1}{\rho}\left(\frac{\partial \rho}{\partial T}\right)_{p}
$$

Air, over the temperature range of concern here $(300 \leq \mathrm{T} \leq 900 \mathrm{~K})$, behaves approximately as an ideal gas so $\bar{\beta}=1 / \overline{\mathrm{T}}$.

\subsubsection{Boussinesq Approximations}

Treating the density as presented in (10) is similar to applying one of the so-called Boussinesq approximations (see Reference 11), although in the Boussinesq approximation, $\overline{\mathrm{T}}$ is usually $\mathrm{T}_{\infty}$. Since $\overline{\mathrm{T}}$ here is yet to be specified (10) has lost no generality. Substituting (10) into (2) and assuming the pressure gradient is due solely to the weight of the fluid, then the momentum equation reduces to 


$$
\frac{\mathrm{d}}{\mathrm{dx}} \int \rho \mathrm{u}^{2} \mathrm{dy}+\tau_{0}-\bar{\rho} \mathrm{g} \bar{\beta} \int(\mathrm{T}-\overline{\mathrm{T}}) \mathrm{dy}=0
$$

where the limits of integration have been dropped for convenience. Note, the assumption regarding the pressure gradient is true, in the strictest sense, only under hydrostatic conditions, but is approached closely at low velocities and for $\Delta \rho / \rho \ll 1$ z.long the channel, or equivalently $\bar{\beta}(\mathrm{T}-\overline{\mathrm{T}}) \ll 1$. This latter condition is implied in the the so-called second Boussinesq approximation (see Reference 11) and allows treating the density in the inertia term of equation (12) together with the remaining fluid properties as constants evaluated at the channel mid-height. Consequently, under the assumption of fully developed flow, equation (12), for uniform area channels, reduces to

$$
\tau_{0}=\tilde{\rho} \mathrm{g} \tilde{\beta} \int(\mathrm{T}-\tilde{\mathrm{T}}) \mathrm{dy}
$$

where the tilde signifies average values over the channel. That is, the buoyancy force is balanced by the viscous force and, consequently, there is no fluid acceleration along the channel. Under these simplifying assumptions, therefore, Equation (13), with (4), (8), and (9) can, for a constant property fluid, be used to estimate the flow rate along the channe..

Substituting (8) and (9) into (3) and (13), and with the aid of Fourier's law results in three equations as

and

$$
\begin{gathered}
\mathrm{T}_{0}=\mathrm{T}_{\mathrm{m}}+\frac{\mathrm{q}^{\prime}}{2.5(9)}\left(\frac{\ell}{\mathrm{k}}\right) \\
\mathrm{V}=\left(\frac{\ell^{2}}{3 \tilde{\mu}}\right) \tilde{\rho} \tilde{\beta} \mathrm{g}\left[\left(\mathrm{T}_{0}-\tilde{\mathrm{T}}\right)-\frac{5}{6}\left(\mathrm{~T}_{0}-\mathrm{T}_{\mathrm{m}}\right)\right]
\end{gathered}
$$

$$
\mathrm{T}_{\mathrm{m}}=\mathrm{T}_{\infty}+\frac{\mathrm{QL}}{\mathrm{mc}_{\mathrm{p}}}
$$

To solve (14)-(16), first a mass flow rate is assumed and, based upon some given linear heat flux and channel length, (16) is solved for the channel ouilet temperature. Equation (14) is then solved for the fuel plate outlet temperature. This temperature data is used in (15) and the channel velocity is calculated. This velocity is compared to that implied by the assumed mass flow rate. If the values are within some acceptable level of error, the calculation is terminated. Otherwise, (16) is returned to with a modified mass flow rate and the iteration loop continued until convergence. If need be, the heat flux input is modified until the solution obtained provides the niass flow rate and wall heat flux along the channel that produce a fuel plate temperature at the channel outlet equal to the melt temperature of 
the fuel $i \approx 900 \mathrm{~K}$ ). The results obtained from this modeling approach are discussed in Section 3.

It is easily veriffed that, under low flow and heat transfer rates, the Boussinesq approximations are good approximations. ${ }^{12}$ For flow along nuclear fuel plates, however, where heat transfer rates are relatively high, the Bowssinesq assumptions break down. That is, the condition $\ddot{\beta}(T-T) \ll 1$ is no longer met. In fact, $\beta(\mathrm{T}-\tilde{\mathrm{T}})$ for the ATR system where the inlet and outlet temperatures are approximately 300 and $900 \mathrm{~K}$, respectively, is 0.5 . As discussed later, this ill condition results in' a conservative (low) estimate of the critical power level under the constraining Boussinesa approximations ${ }^{2}$. The following section presents a method for calculating the heat transfer along the fuel plates that does not rely on the Boussinesq approximations, but rather allows the fluid properties to vary along the channel.

\subsection{Non-Botbsianma (Variable Properties)}

Given a surface heat flux, low Rayleigh number flow results from a large aspect ratio, $L / b$. With low Rayleigh number flow and relatively high heat fluxes, we temperature rise over the channel length becomes significant and the assumption regarding constant properties must be reevaluated. As will be seen from results presented below, the character of this type of now, for the ATR study, begins to diverge from that of Boussinesq flow at a $\mathrm{Ra} \leq 0.1$, and becomes significant for $\mathrm{Ra} \leq 0.001$. Below this latier Ra threshold, the Boussinesq flow approximations result in an overly conservative (low) estimate of the plate/fluid heat transfer rate. As mentioned earlier, for the ATR analysis, $R a \approx 10^{-5}$, and is thus outside the threshold of Boussinesq flow.

Returning to (2) with the density relationship defined by (10), but including the pressure and fluid weight terms results in

$$
-\frac{d}{d x} \int \rho u^{2} d y-r_{0}+\tilde{\rho} g \ddot{\beta}(T-\tilde{T}) d y-\frac{d p^{*}}{d x} \ell-\tilde{\rho} g \ell=0
$$

where $\frac{\mathrm{dp}^{*}}{\mathrm{dx}}$ is an estimate of the pressure gradient which, as discussed later, is obtained elsewhere. From (17), an equation similar to (15) is obtained as

\footnotetext{
${ }^{2}$ For air, the linearized density given by equation (10) (also known as a simplified equation of state) produces
} ar error of $6 \%$ for $\bar{\beta}(\mathrm{T}-\tilde{\mathrm{T}})=0.25$, but this ertor increases to $2.5 \%$ for $\bar{\beta}(\mathrm{T}-\tilde{\mathrm{T}})=0.5$. Also, for $\dot{\beta}(\mathrm{T}-\dot{\mathrm{T}})=0.5$, $\Delta \rho / \rho \approx 1$ rendering the Boussinesq approximations inappropriate. Nevertheless, to this investigator's knowledge, all efforts to model natural circulation between parallel vertical plates have employed the Boussinesq approximations. 


$$
\begin{gathered}
\frac{d V}{d x}=-\frac{2.5 \tilde{\mu}}{\tilde{\rho} \ell^{2}\left[1+2 \ddot{\beta}\left(\tilde{T}-T_{m}\right)\right]}+\frac{g \tilde{\beta}}{\tilde{V}\left[1+2 \tilde{\beta}\left(\tilde{T}-T_{m}\right)\right]}\left[\frac{5}{6}\left(T_{0}-\tilde{T}\right)-\frac{25}{36}\left(T_{0}-T_{m}\right)\right]- \\
\frac{5}{6 \overline{\mathrm{V}}\left[1+2 \tilde{\beta}\left(\tilde{T}-T_{m}\right)\right]}\left(\frac{1 \mathrm{dp}^{*}}{\tilde{\rho} \mathrm{dx}}+\mathrm{g}\right) .
\end{gathered}
$$

As in the previous Boussinesq analysis, a channel wall heat flux is input and a mass flow rate is assumed ${ }^{3}$, but now (18) is integrated along only a portion of the channel, $\Delta x$, rather than evaluated across the entire channel length as was (15). The tilde in (18) now represent the average value along $\Delta x$. Since $\Delta x$ can be chosen as small as necessary, the problems encountered with the Boussinesq approximati , that is $\tilde{\beta}(\mathrm{T}-\tilde{\mathrm{T}})>1$, can be eliminated. Now in (18), rather than iterating upon the velocity as before, the pressure gradient is iterated upon until the resulting mass flow rate at $x+\Delta x$ equals that at $x$, thus satisfying continuity. This procedure is continued to the channel outlet at which point the outlet pressure is compared to a reference gage pressure of 0.0 . If a significant difference results, the calculation is restarter: with a newly assumed value of the mass flow rate and the loop continued until the outlet pressure converges to an acceptable error (for the present calculations errors $<10^{-2}$ were considered acceptable). The convergence rate of this algorithm is strongly dependent upon the means of updating the pressure gradient during the iteration process and upon the initial estimate of $\frac{\mathrm{dp}^{*}}{\mathrm{dx}}$. Discussed below is a method used to estimate the initial value of the pressure gradient term, which, when coupled with the subsequent updating algorithm, produces a rapid rate of convergence.

The method is similar to one used by Baker ${ }^{13}$ but with buoyancy terms included. The approach is basically an integral approach representing the pressure gradient as

$$
\left.\frac{\mathrm{dp}}{\mathrm{dx}}\right|_{\text {Initial }}=\frac{1}{\ell}\left[-\frac{3 \tilde{\mathrm{V}} \tilde{\mu}}{\ell}+\frac{\dot{\mathrm{m}}^{2}}{\tilde{\rho}^{2} \ell} \frac{\mathrm{d} \tilde{\rho}}{\mathrm{dx}}\right]+\tilde{\rho} \tilde{\beta} \mathrm{g} \int(\mathrm{T}-\tilde{\mathrm{T}}) \mathrm{dy}-\tilde{\rho} g \ell
$$

All the information on the right hand side of (19) is available, including the term $\frac{\mathrm{d} \tilde{\rho}}{\mathrm{dx}}$ from (3) and (10), thus providing a means for obtaining an initial estimate of the pressure gradient. This estimate is then updated using

$$
\left.\frac{d p^{*}}{d x}\right|_{\text {next }}=\left.\frac{d p^{*}}{d x}\right|_{\text {last }}+\Delta\left(\frac{d p^{*}}{d x}\right)
$$

where the $\Delta$ (correction) term will drive the solution toward the conservation of mass. From continuity and a simplified form of the one dimensional momentum equation, it can be shown that the correction term takes the form 14,15

\footnotetext{
${ }^{3}$ A good initial estimate of the mass flow rate is obtained from the Boussinesq approximation of Section 2.3 .
} 


$$
\Delta\left(\frac{\mathrm{dp}^{*}}{\mathrm{dx}}\right)=-\left[\frac{\dot{\mathrm{m}}_{\text {assumed }}-\dot{\mathrm{m}}_{\mathrm{x}+\mathrm{dx}}}{\left.\frac{\ell \mathrm{dx}}{\mathrm{m}_{\mathrm{x}+\mathrm{dx}}} \int \rho \mathrm{dy}\right|_{x+\mathrm{dx}}}\right] .
$$

The results obtained from both the Boussinesq and non-Boussinesq methods discussed above are presented in the following section.

\subsection{RESULTS}

Results from the solution of the equations presented in the previous section are discussed in the following paragraphs. First the Boussinesq model is assessed by comparing results obtained to data from existing analytical models and experimental data at appropriate $\mathrm{Ra}$ and $\mathrm{L} / \mathrm{b}$ values. Next, the natural convection air cooling of the ATR, fuel elements is calculated. For the sake of comperison, the ATR critical fuel plate power is estimated ysing both the Boussinesq model and the non-Boussinesq model. As discussed, the difference between the two results is about a factor of two with the Boussinesq model resulting in a lower, more conservative, estimate of the calculated critical power.

\subsection{Model Assersment}

In this section, results obtained from the Boussinesq model discussed in the previous section are compared with experimental data and with results from tiested models at $\mathrm{Ra} \geq 0.1$. The outcome of these comparisons is used to assess the foundation upon which both the Boussinesq and non-Boussinesq models were developed.

Figure 2 below compares heat transfer results obtained from the present Boussinesq model to the early results from Aung (see Reference 5), and to the more recent correlation of Ramanathan and Kumar (see Reference 2). The comparison is for the average Vusselt number along the plate with an average heat transfer coefficient, $\tilde{h}$, defined as

$$
\tilde{\mathrm{h}}=\frac{\mathrm{q}^{\prime}}{\left(\tilde{\mathrm{T}}_{0}-\mathrm{T}_{\infty}\right)}
$$

The Ramanathan and Kumar correlation was developed based upon an analytical model applied over the range $10 \leq \mathrm{Ra} \leq 3 \times 10^{5}$. The Aung et al. analytical model results presented in Figure 2 were obtained over a range of approximately $0.1<\mathrm{Ra}<10^{4}$. As stated earlier, for the ATR system, $\mathrm{Ra} \approx 10^{-5}$, thus rerdering direct application of either Aung et al. or Ramanathan and Kumar data 


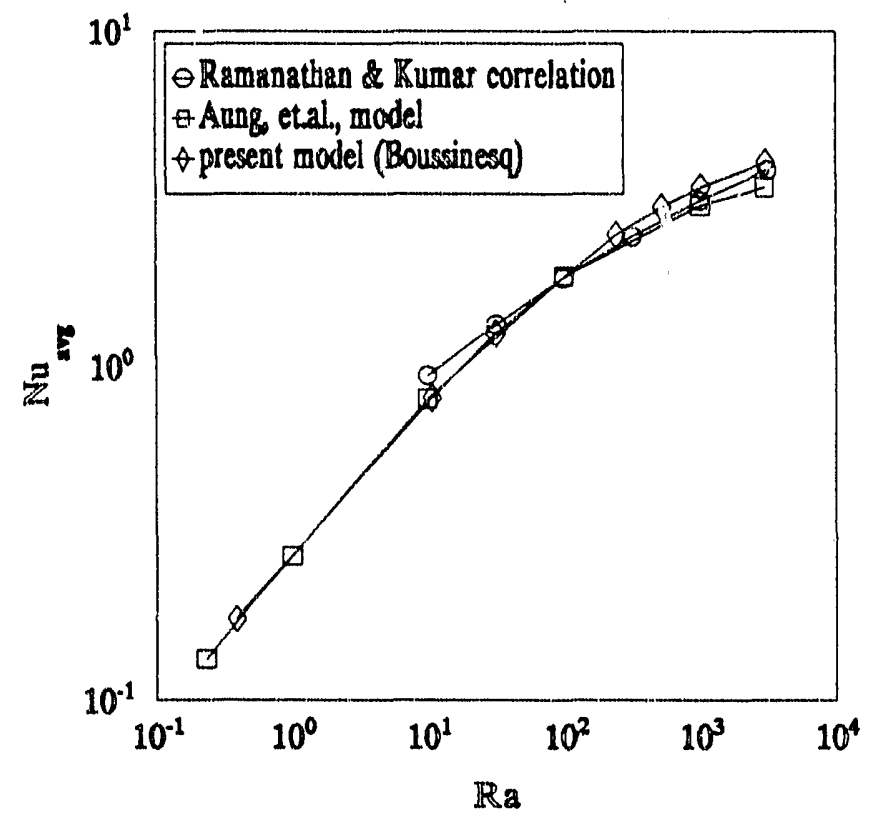

Figure 2. Average channel Nusselt number, Boussinesq model.

inappropriate for the ATR analysis. The results for the present model, shown in Figure 2, are for $.3<\mathrm{Ra}<10^{4}$ (lower $\mathrm{Ra}$ numbers will be addressed in the next section). As indicated, $\mathrm{Nu}_{\text {avg }}$ calculated with the present Boussinesq model is somewhat lower (up to 15\%) than the results of Ramanathan and Kumar for $10<\mathrm{Ra}<100$, but is in excellent agreement with the results of Aung et al. for $0.1<\mathrm{Ra}<100$. At higher $\mathrm{Ra}$, the present model calculates slightly higher values of $\mathrm{Nu}_{\mathrm{avg}}$ than the Aung et al. model and slightly higher values, although to a lesse: extent, than the Ramanathan Kumar correlation. This trend is also exhibited in the data of Figure 3, which compares the outlet channel $\mathrm{Nu}_{\mathrm{L}}$ obtained with the present Boussinesq model with the data of Wirtz and Stutzman (see Reference 6) for $10<\mathrm{Ra}<5000$. The higher heat transfer rates calculated wi'h the present model at Ra $>100$ are unrealistic and are attributed to the assumed inlet boundary conditions, that is the assumption of fully developed flow. Aung (see Reference 5) shows that for Ra $>100$ the entry length becomes an important. consideration. Since the effective shear force along the entry length is higher than that in fully developed flow ${ }^{10}$, neglecting this effect results in relatively high calculated flow rates through the channel. This result is shown in Figure 4 for dimensionless channel lengths, $L^{*}$, greater than about 0.01 , where $L^{*}=\operatorname{Pr} / \mathrm{Ra}$. The results are presented in terms of the dimensionless flow rate $M^{*}$, where $M^{*}=V b / \nu \mathrm{Gr}$. Note that, for $L^{*}>0.01(\mathrm{Ra}<100)$, the fully developed flow assumption is a good assumption. 


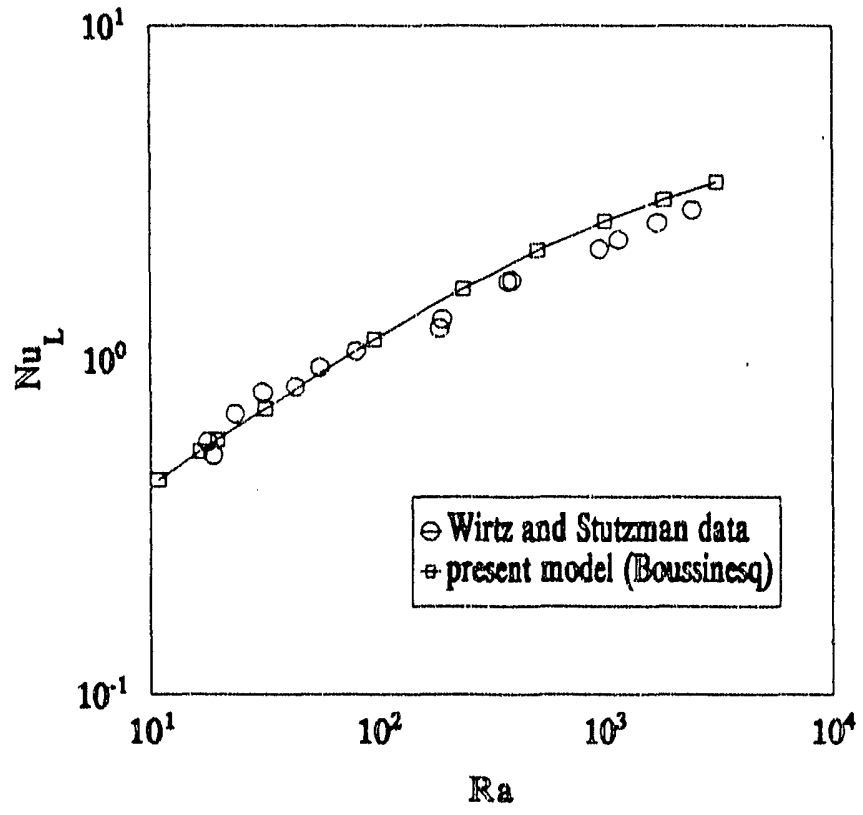

Figure 3. Channel outlet Nusselt number, Boussinesq model.

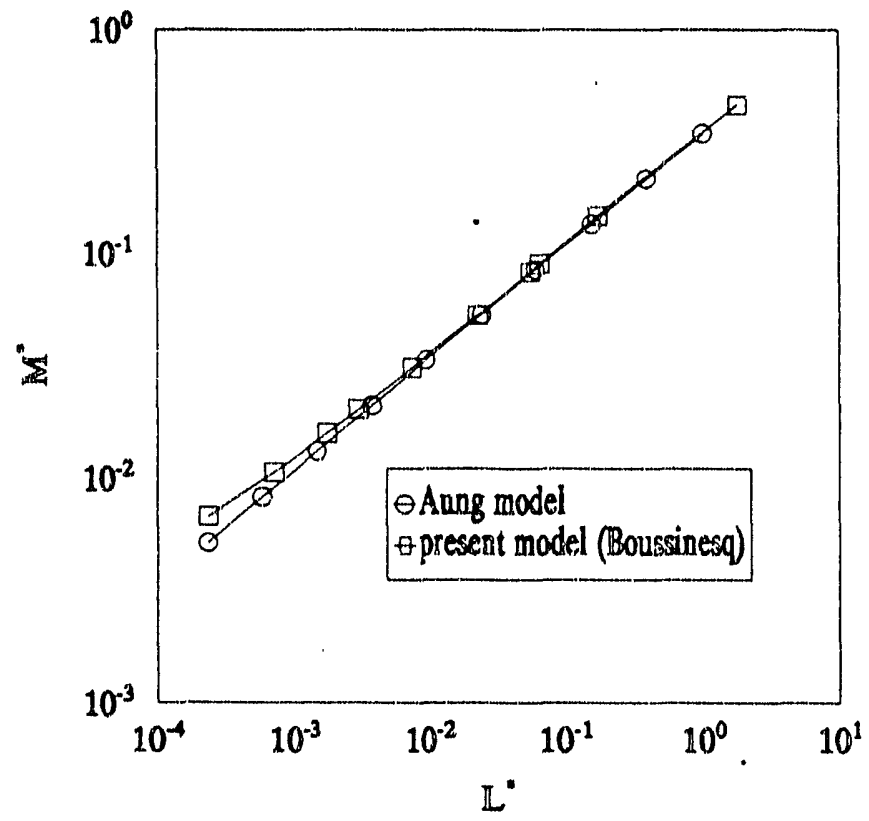

Figure 4. Dimensionless flow rate versus channel length, Boussinesq model. 
The effect of the fully developed flow assumption on the resulting temperature distribution in short channels, $L^{*}<0.01$, is indicated in Figure 5, which shows the temperature along the plate calculated with the present model compared with the data of Wirtz and Stutzman (see Reference 6) for $L^{*} \approx 0.002$ and $L^{*} \approx 0.004$. Although the maximum temperature at these dimensionless channel lengths ( $\mathrm{Ra} \approx 400$ and 200 , respectively) is calculated reasonably well, the nonlinear (developing) temperature profile along the plate is not calculated well. Conversely, Figure 6 shows the result obtained for $L^{*}=0.2$ compared with that of Reference 5 . As indicated, at this dimensionless channel length, the wall temperature becomes linear (fully developed) with axial distance over most of the channel and the present model results agree well with the analytical data. From the definition of the characteristic length, $L^{*}$ for the ATR analysis is on the order of $10^{4}$. At this dimensionless channel length, the assumption of fully developed flow is obviously appropriate.

In summary, the Boussinesq model developed in section 2 has been assessed against available data and analytical results over the limited range of Rayleigh numbers and aspect ratios reported in the literature. Data comparisons have shown that the present Boussinesq model, while slightly over predicting heat transfer rates in short channels $\left(L^{*}<0.01\right)$, produces results that agree well with reported experimental and analytical data at larger channel lengths. It is concluded, therefore, that the Boussinesq model developed in Section 2 has a sound analytical foundation and is applicable over the moderate to low $\mathrm{Ra}$ number range $(0.1<\mathrm{Ra}<100)$. At lower $\mathrm{Ra}$, the non-Boussinesq model, which was developed in the same manner as the Boussinesq model, is used to calculate the channel heat transfer response, as discussed in the following section for the AT'R system.

\subsection{ATR Results}

In this section, results are presented regarding the ATR fuel element natural circulation heat transfer response subsequent to a hypothetical canal draining accident. For all calculations presented here, the air inlet temperatt re is $300 \mathrm{~K}$.

Figure 7 presents a plot of the maximum temperature (channel outlet temperature) versus the input heat flux calculated I 2 sing both the Boussinesq and non-Boussinesq models. Based upon the results shown, the outiet channel surface reaches the approximate melt temperature of $900 \mathrm{~K}$ with an average linear heat flux near $9.5 \mathrm{~W} / \mathrm{m}$ and $17 \mathrm{~W} / \mathrm{m}$ for the Boussinesq and non-Boussinesq models, respectively. This difference in calculated heat flux is reflected in Figure 8 , for $\mathrm{Ra} \approx 10^{-5}$, which shows that $\mathrm{Nu}_{\text {avg }}$ for the non-Boussinesq calculation is approximately twice that for the Boussinesq calculation. This higher heat transfer rate is due to the higher flow rates calculated with the variable 


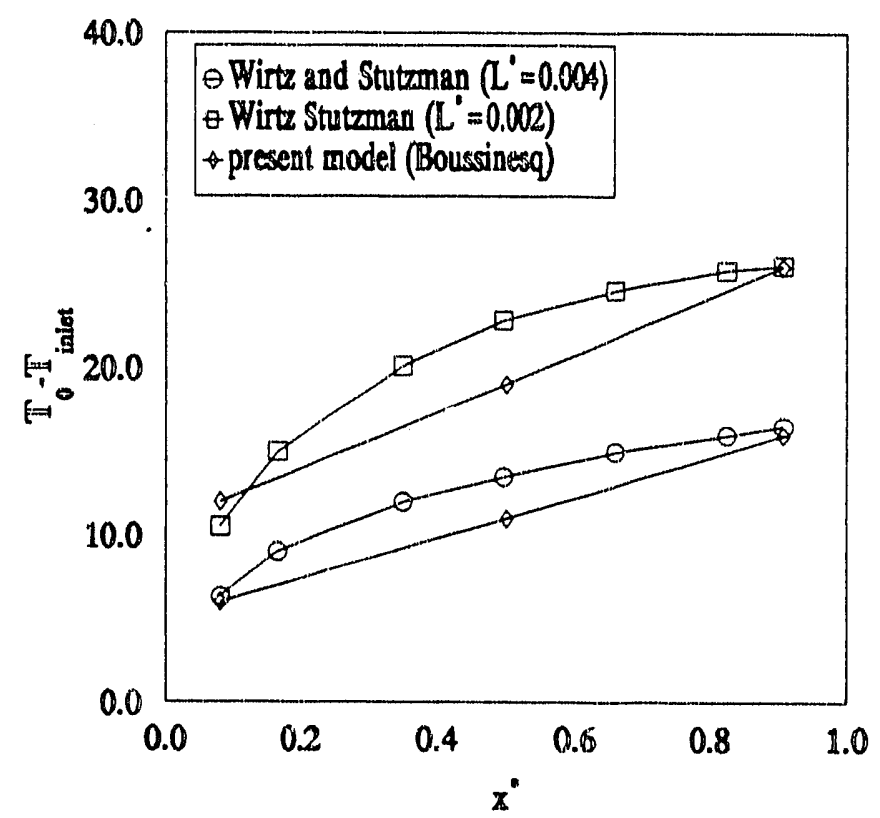

Figure 5. Surface to inlet temperature difference along the channel, $L^{*}=0.002,0.004$.

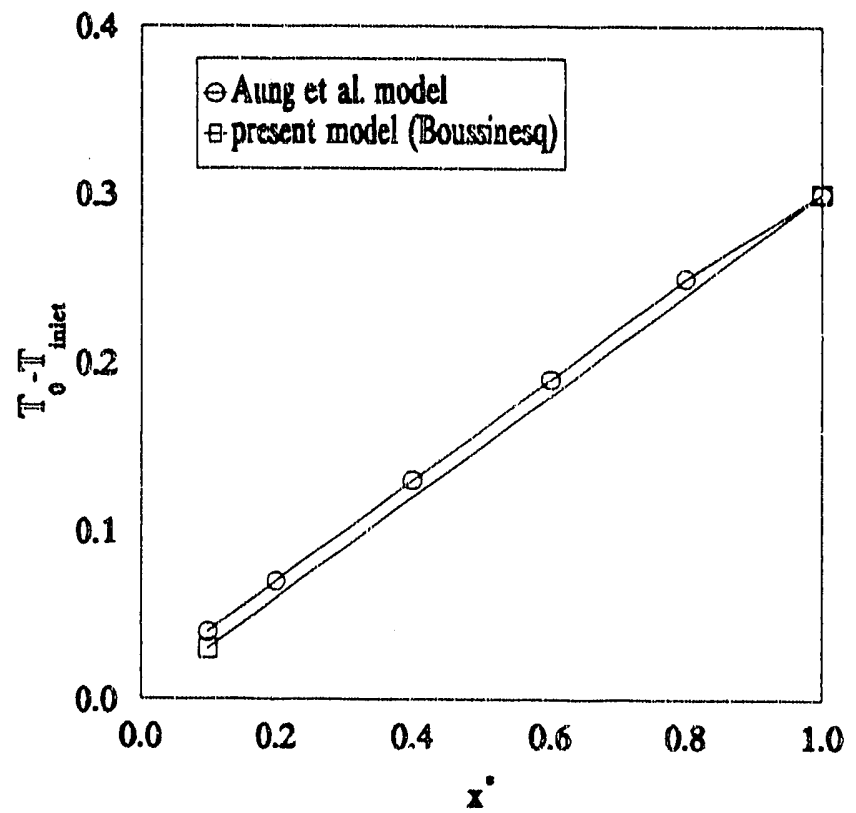

Figure 6. Surface to inlet temperature difference along the channel, $L^{*}=0.20$. 


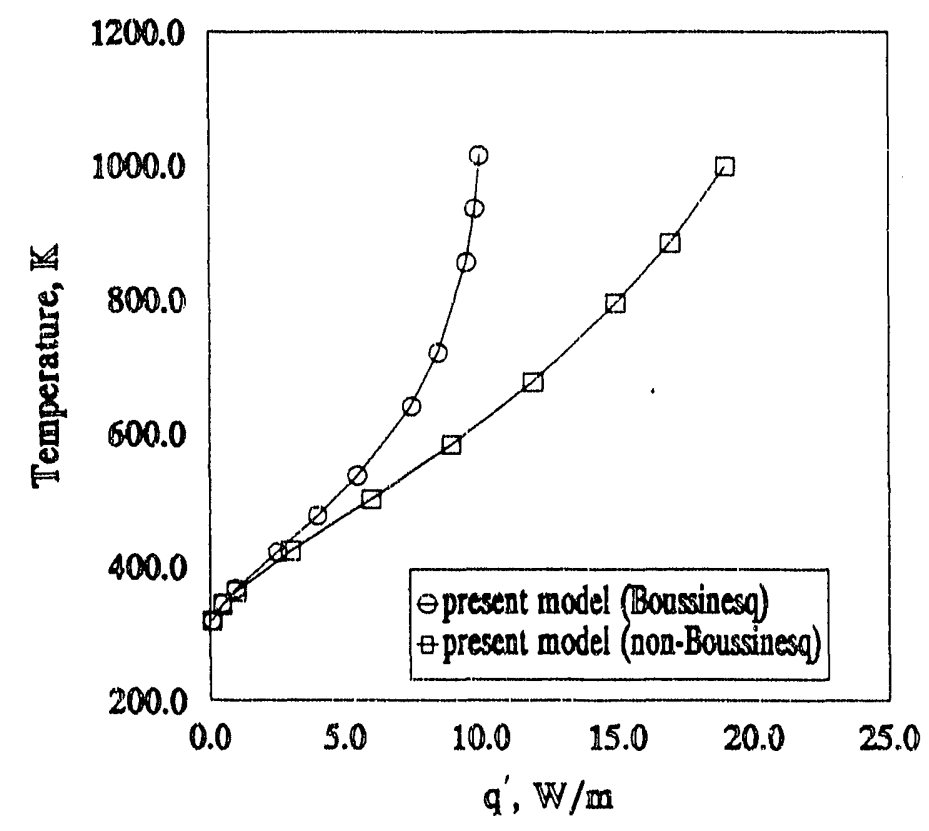

Figure 7. Maximum calculated temperature versus input heat flux.

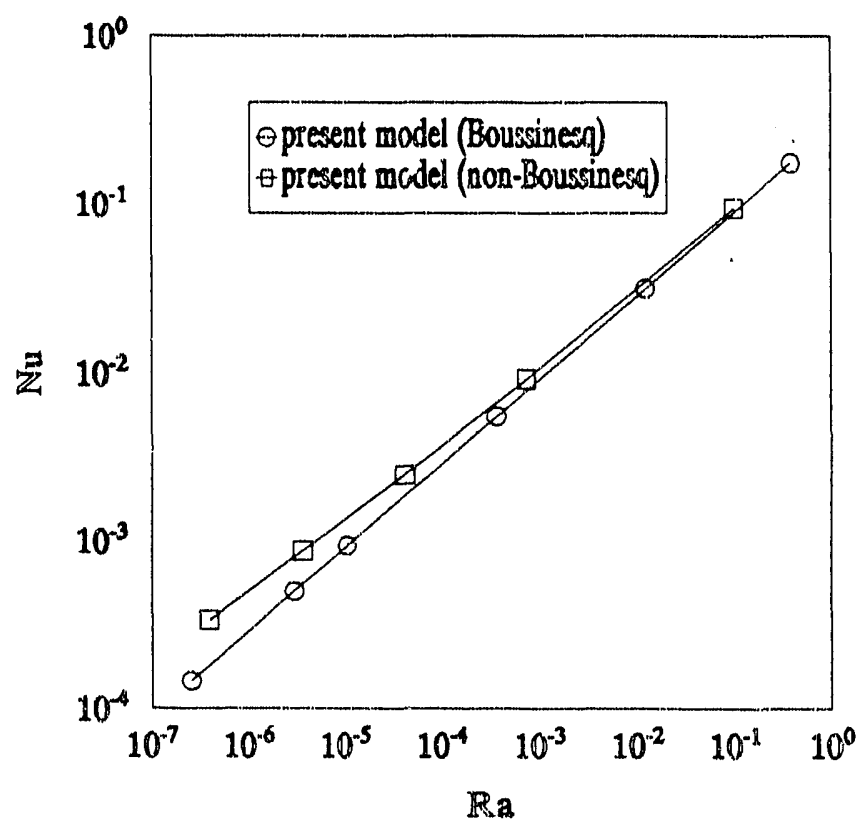

Figure 8. Average Nusselt number along the plate. 
fluid property non-Boussinesq model, as indicated in Figure 9. Note in Figure 8 that as Ra increases, an effect obtained in the data shown by holding the heat flux constant and decreasing the aspect ratio, the non-Boussinesq result asymptotically approaches that of the Boussinesq. Similarly, by holding the aspect ratio constant and decreasing the heat flux, the non-Boussinesq result approaches that of the Boussinesq, as shown in Figures 7 and 9.

Note in Figure 9 that, as the input heat flux is increased, the mass flow rate reaches a maximum and then begins to decrease. This behavior is easily understood upon recognizing the relationship between the buoyancy force and the change in fluid density with temperature. Figure 10 shows the fluid density of air as a function of temperature. Note that the change in density with temperature tends to level off for $\mathrm{T}>500 \mathrm{~K}$. Since the buoyancy force is proportional to the density gradients within the system, this force too levels off for $T>500 \mathrm{~K}$, as shown in Figure 11, for the case of the Boussinesq model. Meanwhile, the viscosity of the air continues to increase with temperature, as shown in Figure 12; consequently, the flow rate through the channel must decrease as shown in Figure 9.

Figure 13 compares the temperature drop from the fuel plate surface to some point $\eta$ in the fluid. The results presented are for the non-Boussinesq model with an input linear heat flux of 17 $\mathrm{W} / \mathrm{m}$. is indicated, the overall magnitude of temperature drop decreases from the inlet to the outlet of the channel. This decrease is due to the variable property effect, specifically the increasing thermal conductivity of the fluid with increasing temperature.

Due to axial power peaking along the fuel plate, the heat flux along the fuel is not constant but, assuming negligible conduction in the direction parallel to the channel, varies as the local volumetric heat generation rate times the thickness of the fuel. The local volumetric heat generation rate is obtained from Reference 16 and is related to the maximum volumetric heat generation rate as

$$
\mathrm{q}^{\prime \prime \prime}(\mathrm{x})=\mathrm{q}_{\max }^{\prime \prime \prime}\{\cos [0.058(39.37 \mathrm{x}-23.82)]\}
$$

where $x$ is measured in meters from the bottom of the channel and $q^{\prime \prime \prime}(x)$ and $q_{\max }^{\prime \prime \prime}$ are the local and peak heat generation rates within the fuel element, respectively. Now, from earlier results,

$$
\mathrm{q}_{\mathrm{avg}}^{\prime \prime \prime}=\frac{17}{0.068}\left(\frac{2}{\mathrm{t}}\right)=984 \mathrm{~kW} / \mathrm{m}^{3}
$$

where $0.068 \mathrm{~m}$ is 9 , the average width of the fuel plate, and $t$ is the fuel thickness ${ }^{4}$.

\footnotetext{
${ }^{4}$ In equation (24) the average wall heat flux is multiplied by two to account for both of the channel walls.
} 


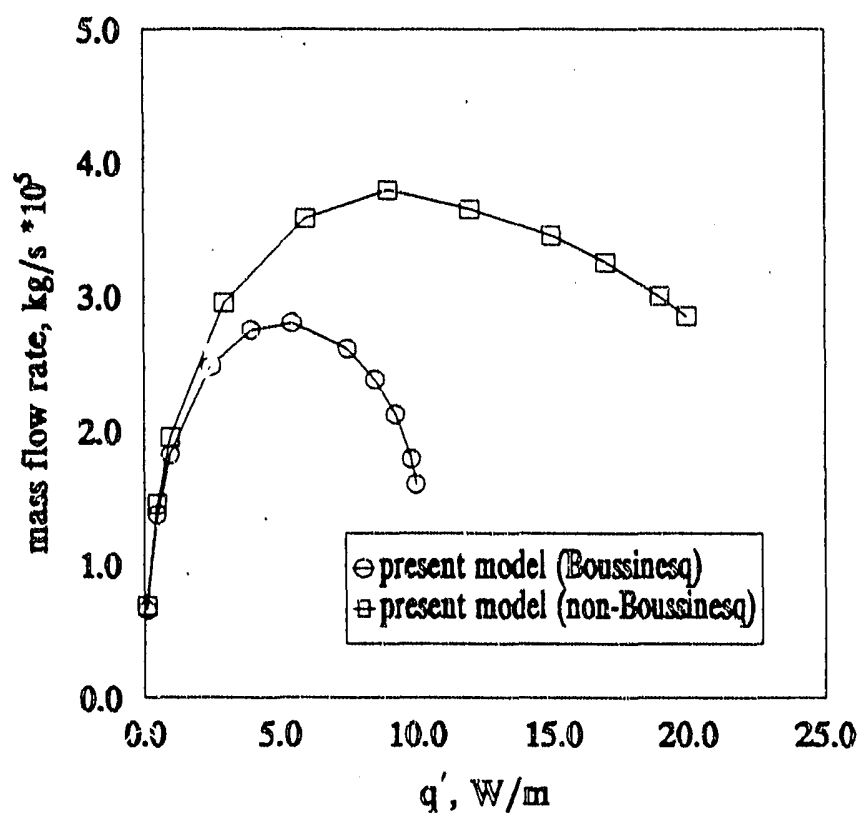

Figure 9. Channel mass flow rate versus input heat flux.

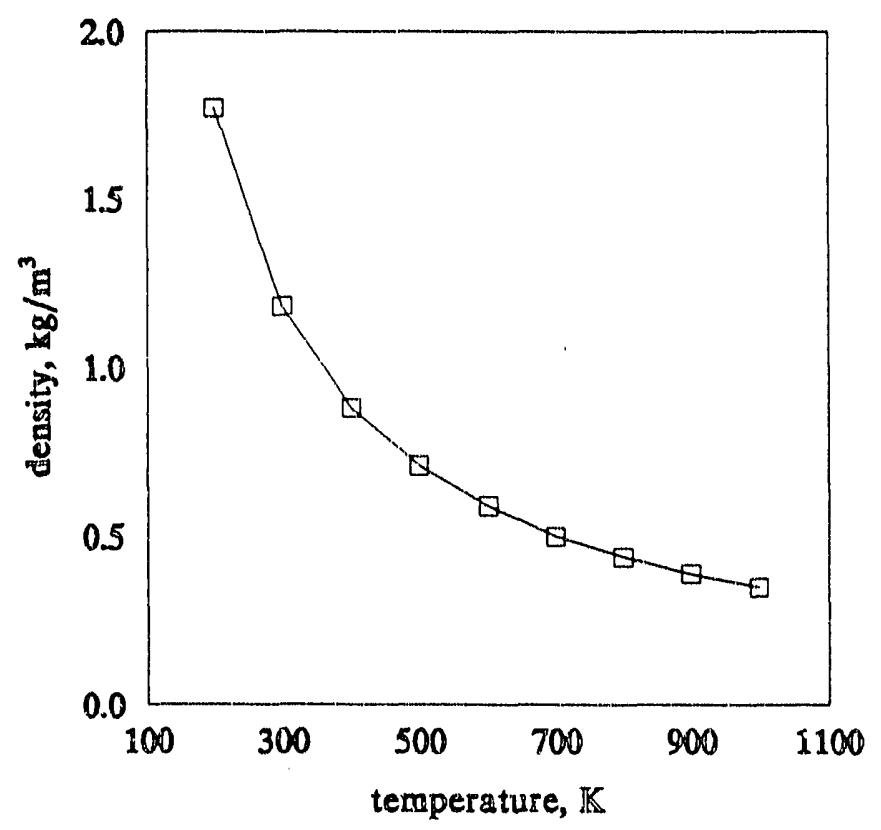

Figure 10. Air density as a function of temperature. 


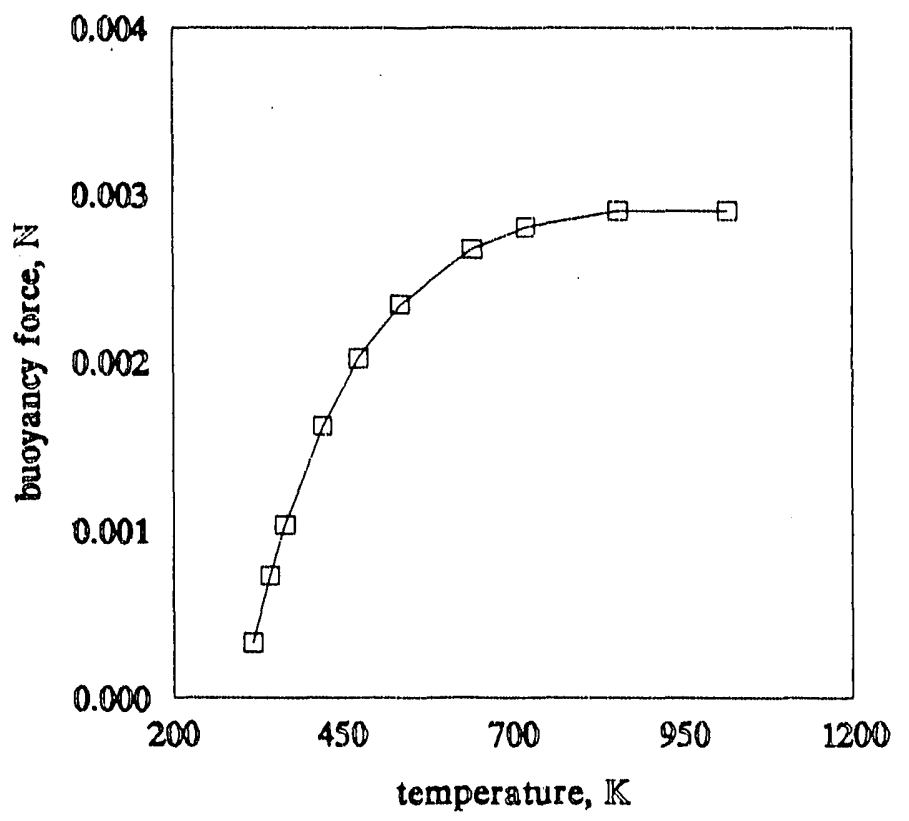

Figure 11. Buoyancy force as a function oi temperature.

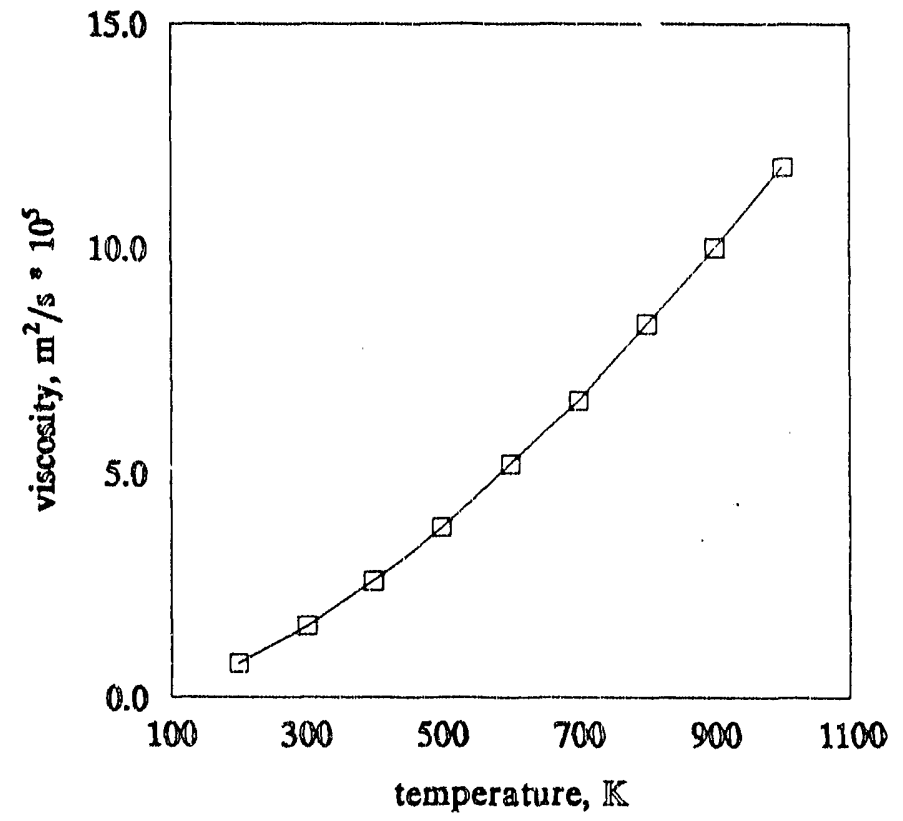

Figure 12. Air viscosity as a function of temperature. 


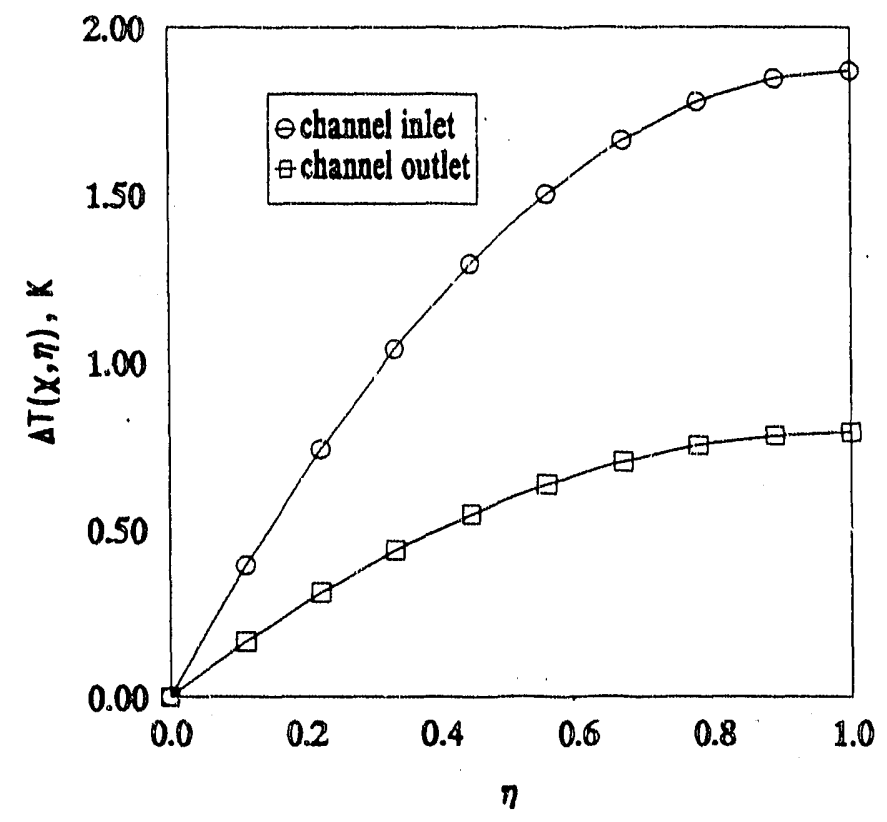

Figure 13. Temperature drop from the fuel plate to the fluid.

Also, the average heat generation rate can be definea as,

$$
q_{a v g}^{\prime \prime \prime}=\frac{\int q^{i \prime \prime}(x) d x}{L},
$$

where $\mathrm{L}$ (length of the fuel plate) is in meters. Substituting (23) into (25) results in the following

Therefore,

$$
\frac{\mathrm{q}_{\max }^{\prime \prime \prime}}{\mathrm{q}_{\text {avg }}^{\prime \prime \prime}}=1.412
$$

$$
\frac{\mathrm{q}^{\prime \prime \prime}(\mathrm{x})}{\mathrm{q}_{\text {avg }}^{\prime \prime \prime}}=(1.412)\{\cos [0.58(39.37 \mathrm{x}-23.82)]\}
$$

Figure 14 shows a plot of (27) along the plate. Figure 15 shows the calculated temperature profile along the plate for both the case of constant heat flux and the case of variable heat flux derived from (27). Since $\mathrm{x}$-direction conduction within the fuel plate will tend to flatten the effects of power per.king, the resulting temperature profile along the plate would tend to be somewhere between the two profiles shown in Figure 15. 


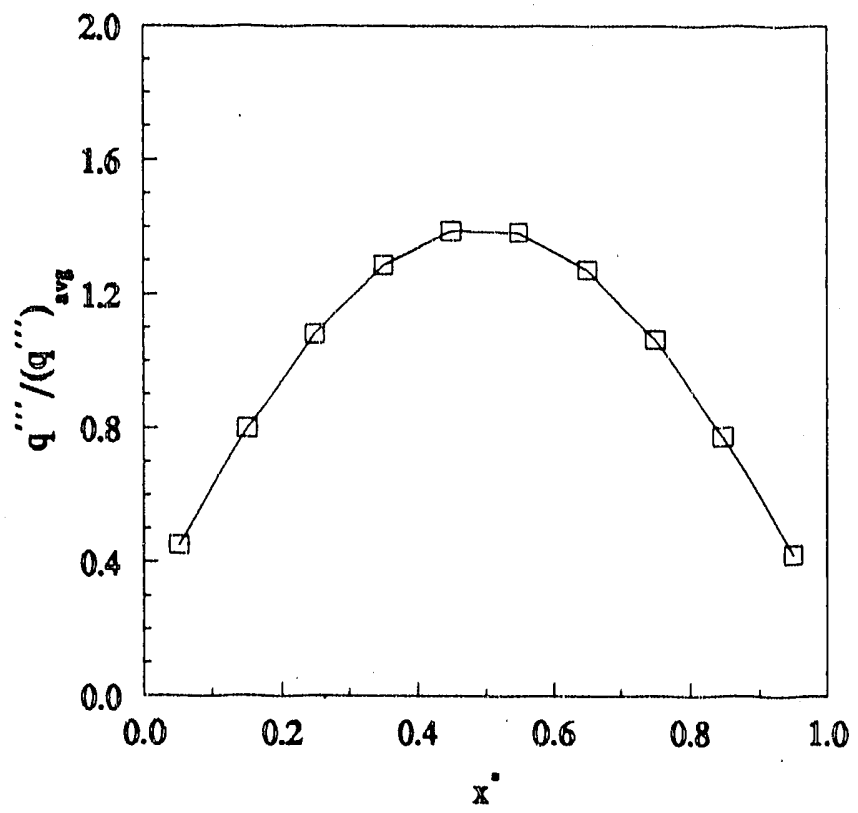

Figure 14, Ratio of local to average volumetric heat generation rate along fuel element.

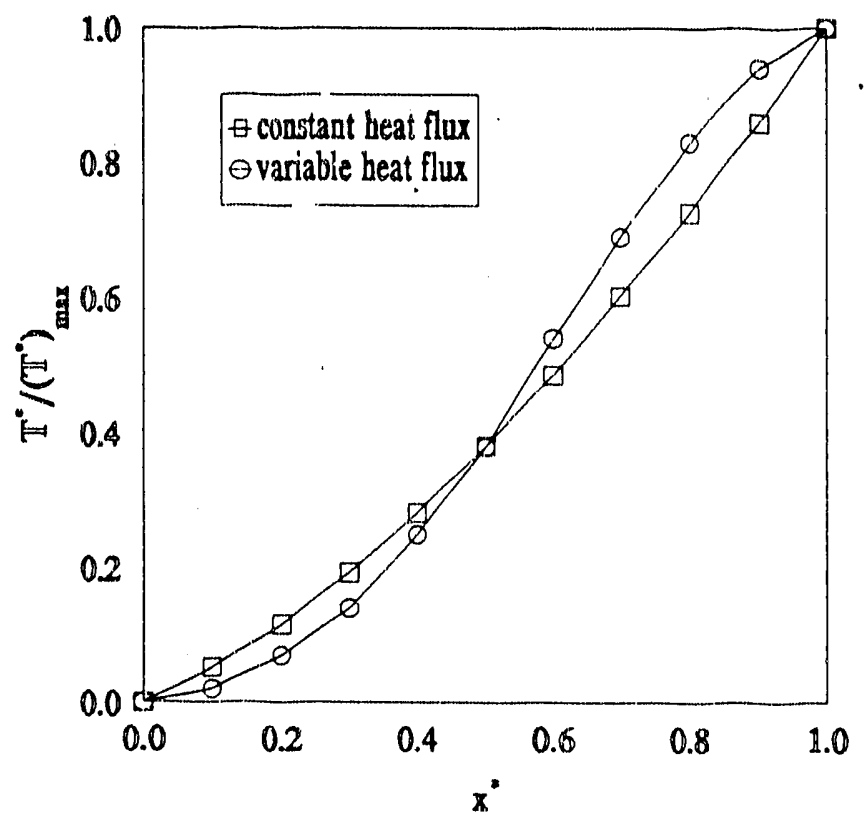

Figure 15. Dimensionless temperature calculated from constant and variable power profiles. 
It was mentioned at the outset that, if need be, a conduction solution would be coupled to the boundary layer solution. It has been determined that, for the ATR analysis, this exercise is unnecessary. From the fuel element thermal properties given in Reference 17, the uranium aluminide fuel has a thermal conductivity, which is approximately constant over the temperature range of interest, of about $42 \mathrm{~W} / \mathrm{m}-\mathrm{K}$. The thermal conductivity of the aluminum clad is also neariy constant over the same temperature range at a value near $183 \mathrm{~W} / \mathrm{m} \cdots \mathrm{K}$. Defining an auxiliary heat transfer coefficient as

$$
\overrightarrow{\mathrm{h}}=\frac{\mathrm{q}^{\prime}}{\mathrm{g}\left(\tilde{\mathrm{T}}_{0}-\tilde{\mathrm{T}}_{\mathrm{m}}\right)} \approx 140 \mathrm{~W} / \mathrm{m}^{2} \mathrm{~K}
$$

where the value was obtained from the calculations presented earlier, and evaluating the Biot number, $B i$, as

$$
B i=\frac{\hat{h} \varphi}{\hat{k}}
$$

where $\Psi$ is half of the plate thickness $(\approx 0.0006 \mathrm{~m})$ and $\hat{k}$ is the sverage material thermal conductivity $(\approx 112 \mathrm{~W} / \mathrm{m}-\mathrm{K})$, results in a $\mathrm{Bi} \approx 10^{-3}$. Ozisik ${ }^{18}$ concludes that a one-dimensional transient temperature distribution within a solid can be considered uniform with an error less than approximately $5 \%$ if $\mathrm{Bi}<10^{-1}$. For a steady-state analysis such as being considered here, there is obviously a temperature gradient within the fuel and clad but due to the relatively low heat flux and very small spatial distances involved, it can be shown that the temperature differential within the plate is less than $3.0 \mathrm{~K}$. Even if power peaking is accounted for with the maximum heat flux $\approx 17 \mathrm{~W} / \mathrm{m}(1 / 0.068$ $\mathrm{m})(1.4)=350 \mathrm{~W} / \mathrm{m}^{2}$, the resulting temperature differential is less than $5.0 \mathrm{~K}$. It was concluded, therefore, that the calculated surface temperature provided an adequate indication of the limiting temperature for critical power assessment.

In conclusion, therefore, with an average linear heat flux of $17 \mathrm{~W} / \mathrm{m}$, and a fuel element length of $1.2192 \mathrm{~m}$, the power per fuel plate is $(1.2192)(17)(2)=41.5 \mathrm{~W}$. So for 19 fuel plates per elernent, the critical fuel element power is $(19)(41.5)=788 \mathrm{~W}$. Any fuel element in the canals above this power may be assumed to melt subsequent to the hypothetical canal draining accident.

The overall conclusions reached from this investigation are presented in the following section. 


\subsection{CONCLUSIONS}

An investigation of natural convection heat transfer along a cypical ATR fuel elernent subsequent to a hypothetical canal draining accident has been conducted. The objective of this study was tw determine the level of decay heat that can be removed, via natural circulation of air through the fuel assemblies, without exceeding the melting temperature of the fuel $(\approx 900 \mathrm{~K})$. This information can be used in the PRA consequence analysis to calculate the amount of fuel, based upon the fuel life cycle, that is above this critical power level and thus may be assurned to melt.

A literature search concluded that the ATR system aspert ratio and associated Ra were outside the range of existing data or analytical models. Therefore, rather than using possibly inappropriate data, two models were developed from first principles. In the first model, the wel'-known Boussinesq approximations were used. Results from this model, when compared to existing data, indicated a sound analytical foundation. In the second model, the Boussinesq approximations were not used, making the model more general and applicable to the ATR system analysis. Results obtained showed that natural convection air cooling of the ATR fuel elements can sustain a maximum average linear heat nux of $17 \mathrm{~W} / \mathrm{m}$ without exceeding a surface temperature of $900 \mathrm{~K}$. Since a coupled conduction solution was found to be unnecessary, this heat flux translates to a critical element power of $788 \mathrm{~W}$. Any fuel elements stored in the canals that are above this power may, for the purposes of a PRA consequence analysis, be assumed to melt subsequent to a canal draining accident. 


\subsection{REFERENCES}

1. Atkinson, S. A, Eide, S. A., and Thatcher, T. A. Advanced Test Reactor Risk Summary, EGGPRP-1-25, December 1991.

2. Ramanathan, S. and R. Kumar, "Correlations for Natural Convection Between Heat :d Vertical Plates Heated Asymmetrically," ASME Journal of Heat Transfer, Vol. 113, pp. 97+, 1991

3. Elenbaas, W., "Heat Dissipation of Parallel Plates by Free Convection," Physica, Vol. 9, pp. $1+, 1942$.

4. Aung, W., "Fully Developed Laminar Free Convection Between Vertical Plates Heated Asymmetrically," International Journal of Heat and Mass Transfer, Vol., 15, pp. 1577+, 1972.

5. Aung, W., Fletcher, L. S., and Sernas, V., "Developing Laminar Free Convection Between Vertical Plates with Asymmetric Meating," International Journal of Heat and Mass Transfer, Vol. 16, pp. $2293+, 1972$.

6. Wirtz, T. A., and Stutzman, R. J., 1982, "Experimentz on Free Convection Between Vertical Plates With Symmetric Heating," ASME Journal of Heat Transfer, Vol. 104, pp. 501+, 1982.

7. Miyamoto, M., et al., "Development of 'Turbulence Characteristics in a Vertical Free Convection Boundary Layer, Heat Transfer 1982, Vol. 2, pp. 323-t, 1982.

8. Varacalle, D. J., "Natural Convection Cooling Analysis of ATR Fuel Elements and Storage Racks in Air," RE-E-75-033 (EG\&G Internal Report), 1976.

9. Martin, L., Raithby, G. D., and Yovanovich, M. M., "On the Low Rayleigh Number Asymptote for Natural Convection Through an Isothermal, Parallel-Plate Channel, ASME Journal of Heat Transfer, Vol. 113, pp. 899+, 1991.

10. Kays, W. M., and Crawford, M. E., Convective Heat Transfer, McGraw-Hill Book Company, $2^{\text {nd }}$ edition, pp. $45+, 1980$.

11. Gebhart, B., "Buoyancy Induced Fluid Motions Characteristic of Applications in Technology - The 1978 Freeman Scholar Lecture," Journal of Fluids Engineering, Vol. 101, pp. 5+, 1979.

12. Gray, D. D., and Giordini, A., "The Validity of the Boussinesq Approximation for Liquids and Gases," International Journal of Heat and Mass Transfer, Vol. 19, pp. 545+, 1976.

13. Baker, A. J., Finite Element Computational Fluid Mechanics, pp. 345+, McGraw-Hill, 1983.

14. Langerman, M. A., and Lernmon, E. C., "A Multidimensional Finite Element MHD Model of Internal Plasma Flows," Heat Transfer in Thermal Plasma Processing, ASME IITD.Vol. 179, pp. 9+, 1991.

15. Pantankar, S. V., and Spalding, D. B., "A Calculation Procedure for Heat, Mass, and Momentum 
Transfer in Three-Dimensional Parabolic Flows," International Journal of Heat and Mass Transfer, Vol. 15 , pp. $1787+, 1972$.

16. Henschied, J. W., et al., ATR Startup, Zero-Power Experiments, and Comparison With ATR Critical Facility, IN-1136, (Idaho Nuclear Corporation report) December 1967.

17. Polkinghorne, S. T., and Lacy, J. M., Thermophysical and Mechanical Properties of ATR Core Materials, PG-T-91-031, (EG\&G Idaho, Inc., Internal Technical Report), August 1991.

18. Ozisik, M. N., Heat Conduction, John Wiley \& Sons, pg. 16, 1980. 

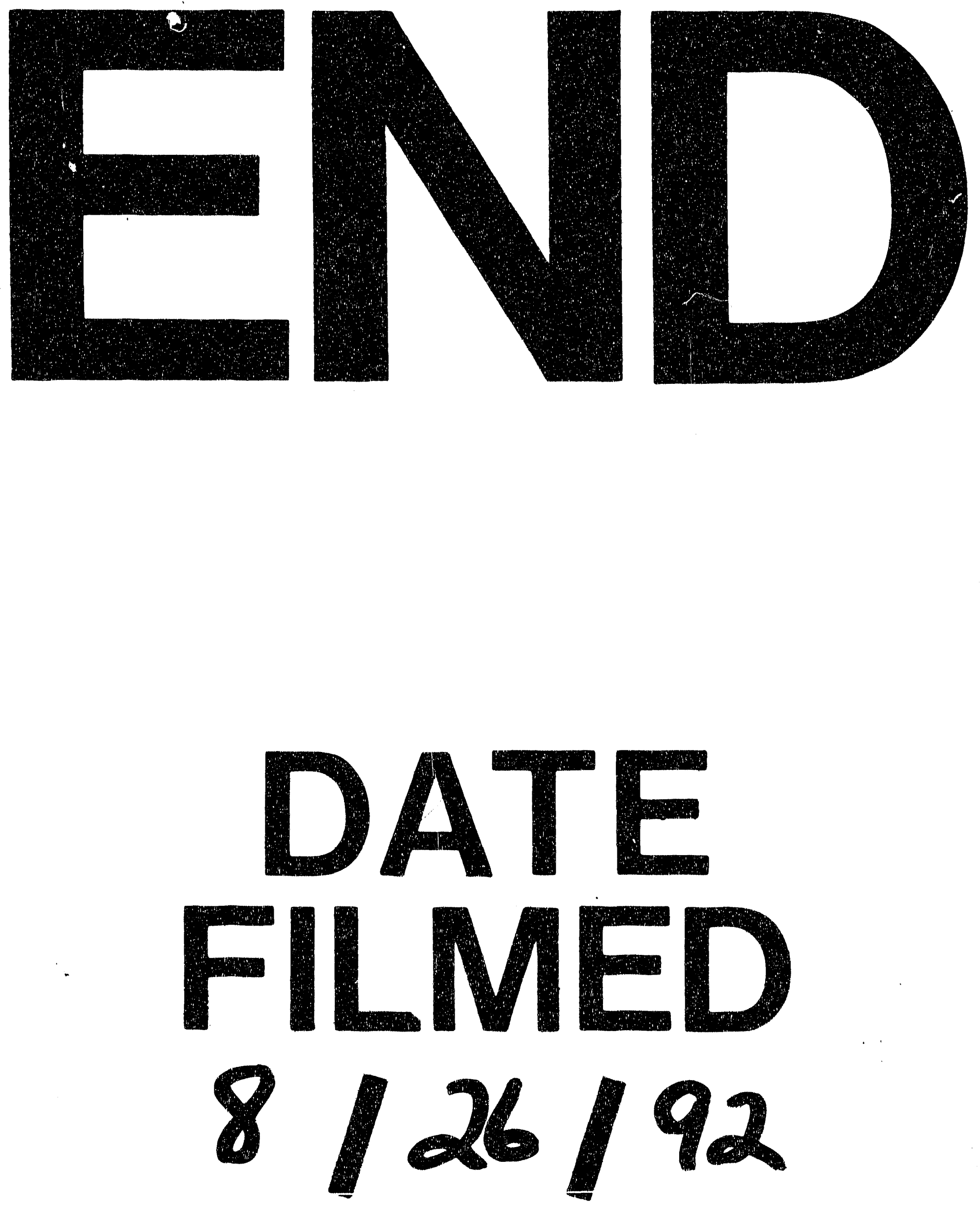
